\title{
Trace element discrimination of arc, slab failure, and A-type granitic rocks
}

Joseph B. Whalen, Geological Survey of Canada, 601 Booth Street, Ottawa, Ontario K1A 0E8, Canada, \& Robert S. Hildebrand, 1401 N. Camino de Juan, Tucson, Arizona 85745, USA

\section{Introduction}

We studied the geochemistry of magmatism before and after collisional deformation in plutons of both the Peninsular Ranges and Sierran batholiths, and found that trace elements can be used to distinguish between arc and slab failure-related granitoids.

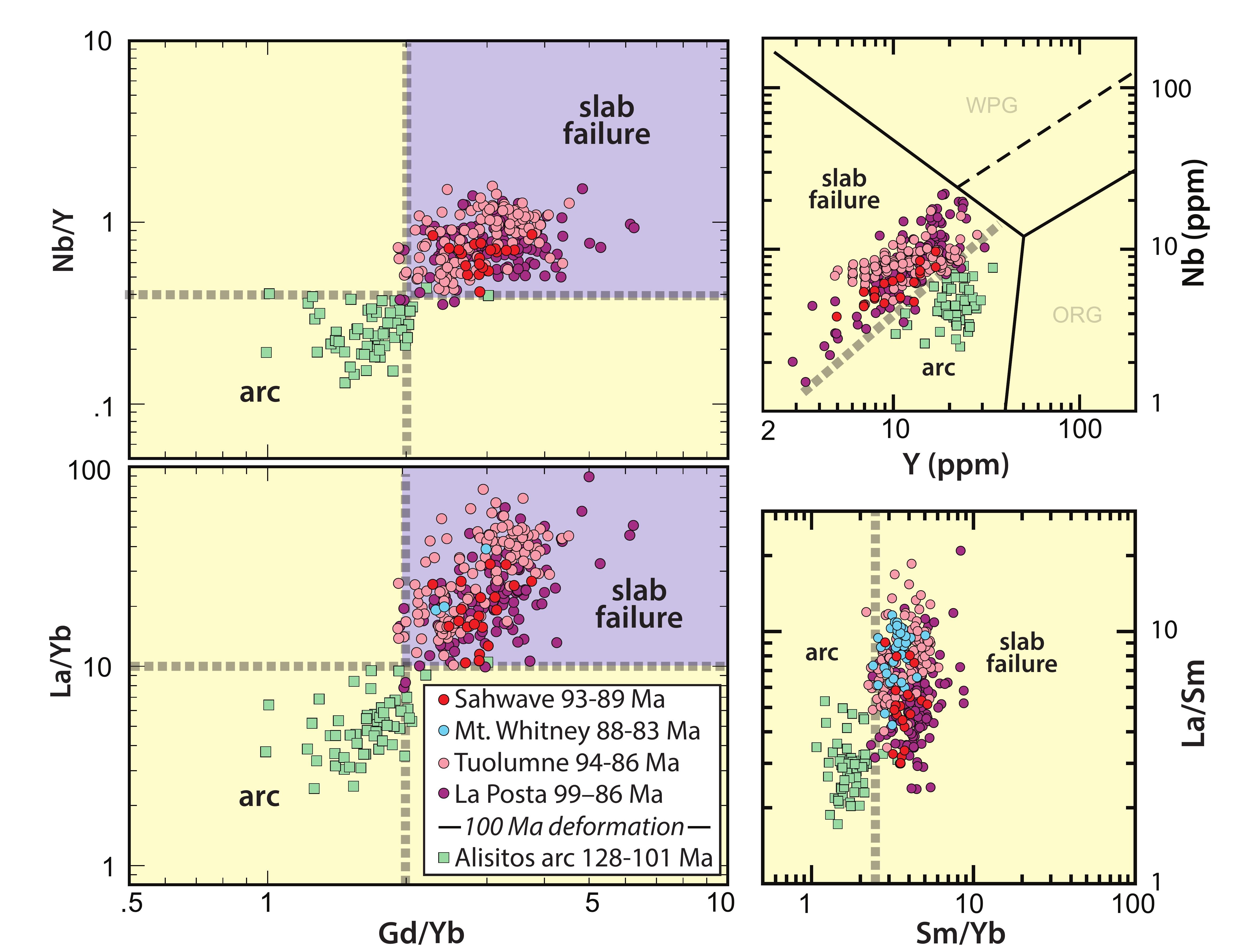

Plutonic samples with 55 to 70 wt. $\% \mathrm{SiO}_{2}$ from the Peninsular Ranges Batholith (Lee et al., 2007), the Sierra Nevada Batholith (Hirt, 2007; Memeti, 2009) and the Sahwave suite of Nevada (van Buer and Miller, 2010) plotted on tectonomagmatic discrimination plots (Hildebrand and Whalen, 2014b, 2017): $\mathrm{Gd} / \mathrm{Yb}$ vs. $\mathrm{Nb} / \mathrm{Y}$ and La/Yb; Sm/Yb vs. La/Sm and $Y$ vs. Nb. Note the high degree of separation of arc from slab failure rocks. This poster adapted from Whalen, J.B., and Hildebrand, R.S., 2019, Trace element discrimination of arc, slab failure, and A-type gra-
nitic rocks: Lithos $348-349$ (2019) 105179

\section{Which samples to use}

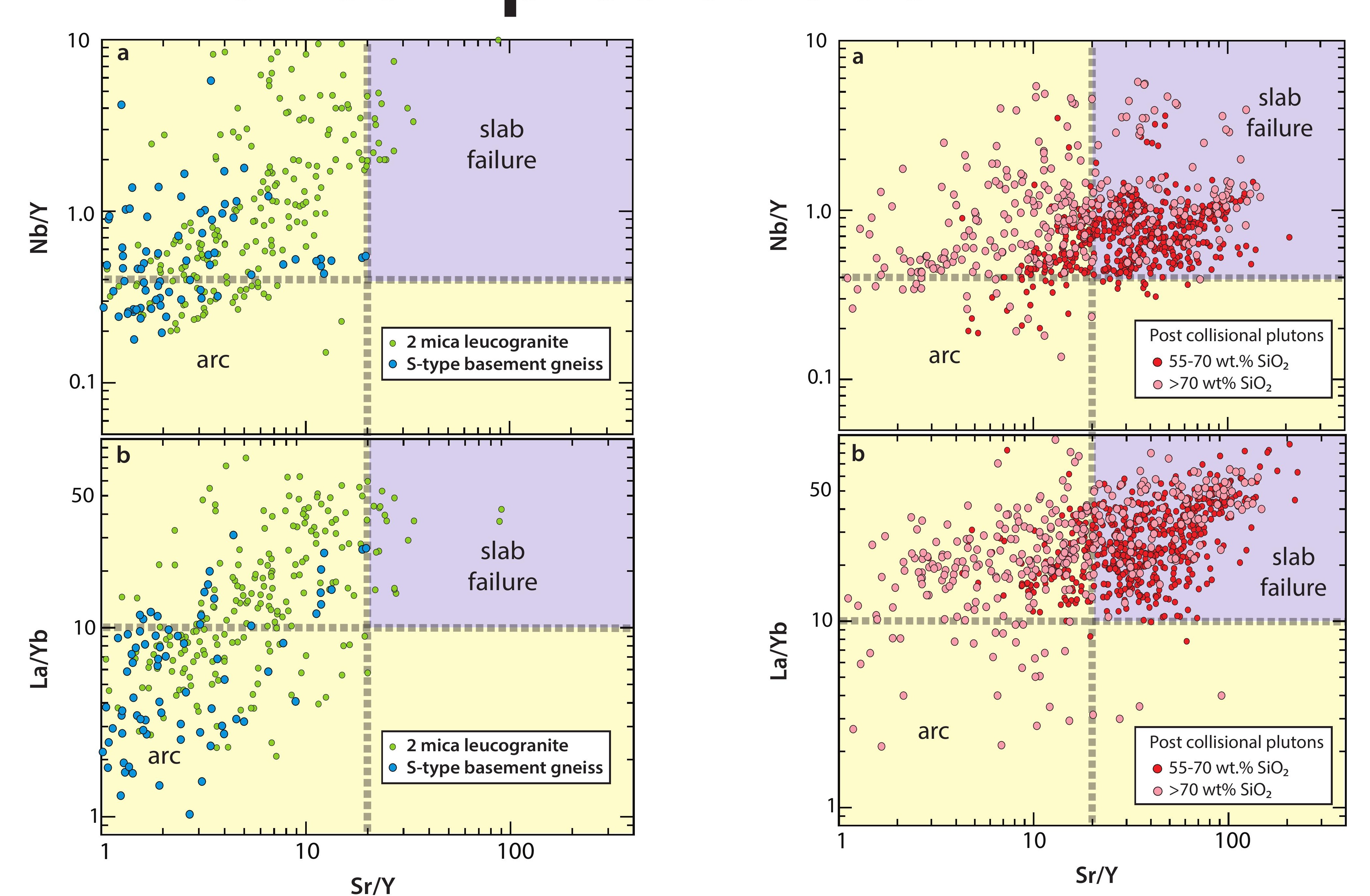

Rocks with high aluminum saturation index ASI, and silica $>70 \%$ should not be plotted on our new discrimination plots as they can give spurious results.

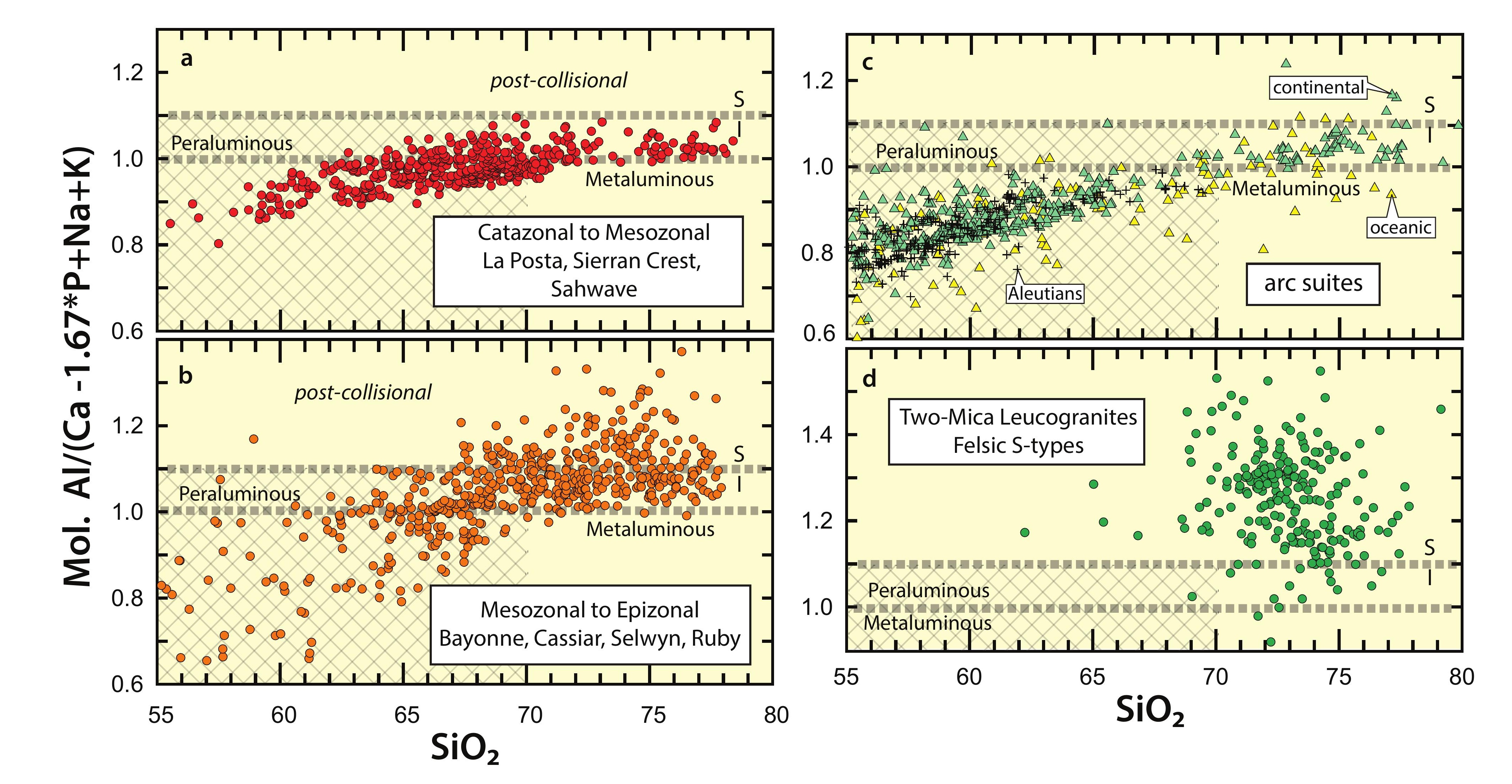

Use samples with $55-70$ wt. $\% \mathrm{SiO}_{2}$ and ASI $<1.1$.

\section{References}

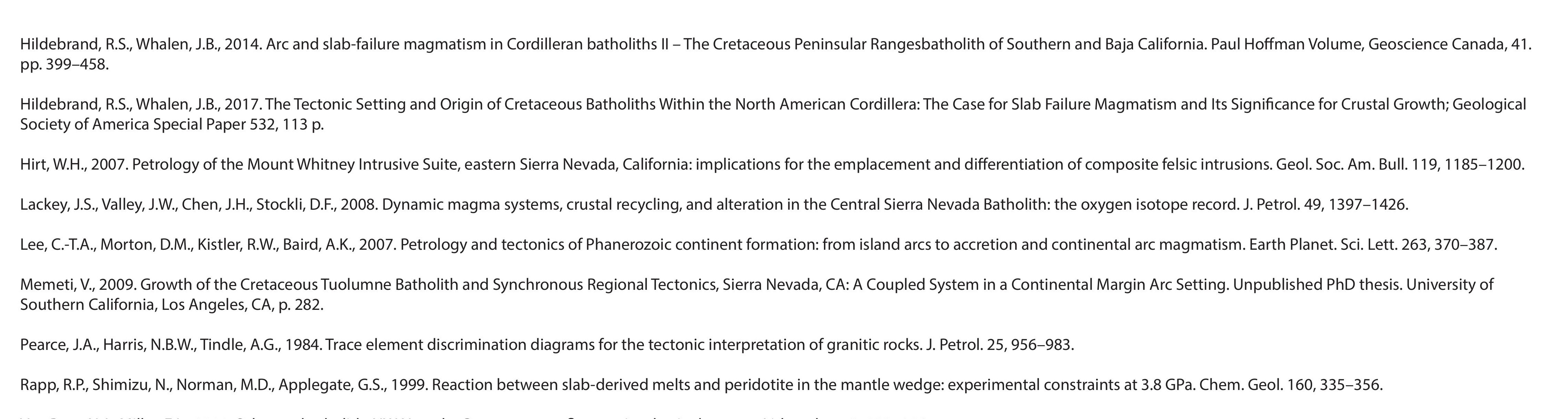

Discrimination diagrams for arc, slab failure and A.type plutonic rocks
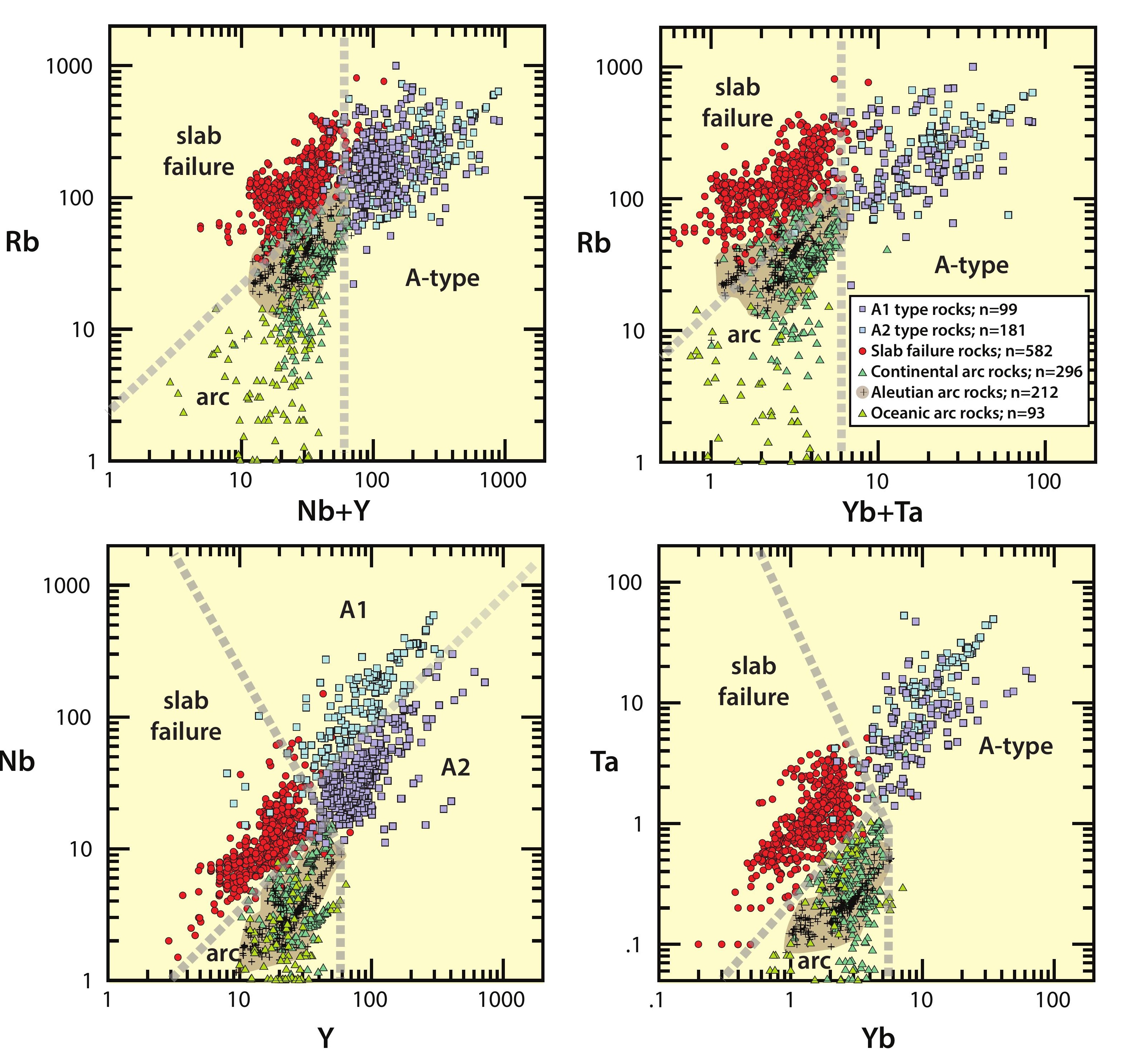

We modified Pearce et al. (1984) granitoid rock discrimination plots to better differentiate l-type arc, slab failure and $A_{1}$ - and $A_{2}$-type granitoid compositions. Due to the relative mobility of $\mathrm{Rb}$ in late fluids caution should be used in utilizing the Rb plots. Original Pearce et al. plots are shown below.

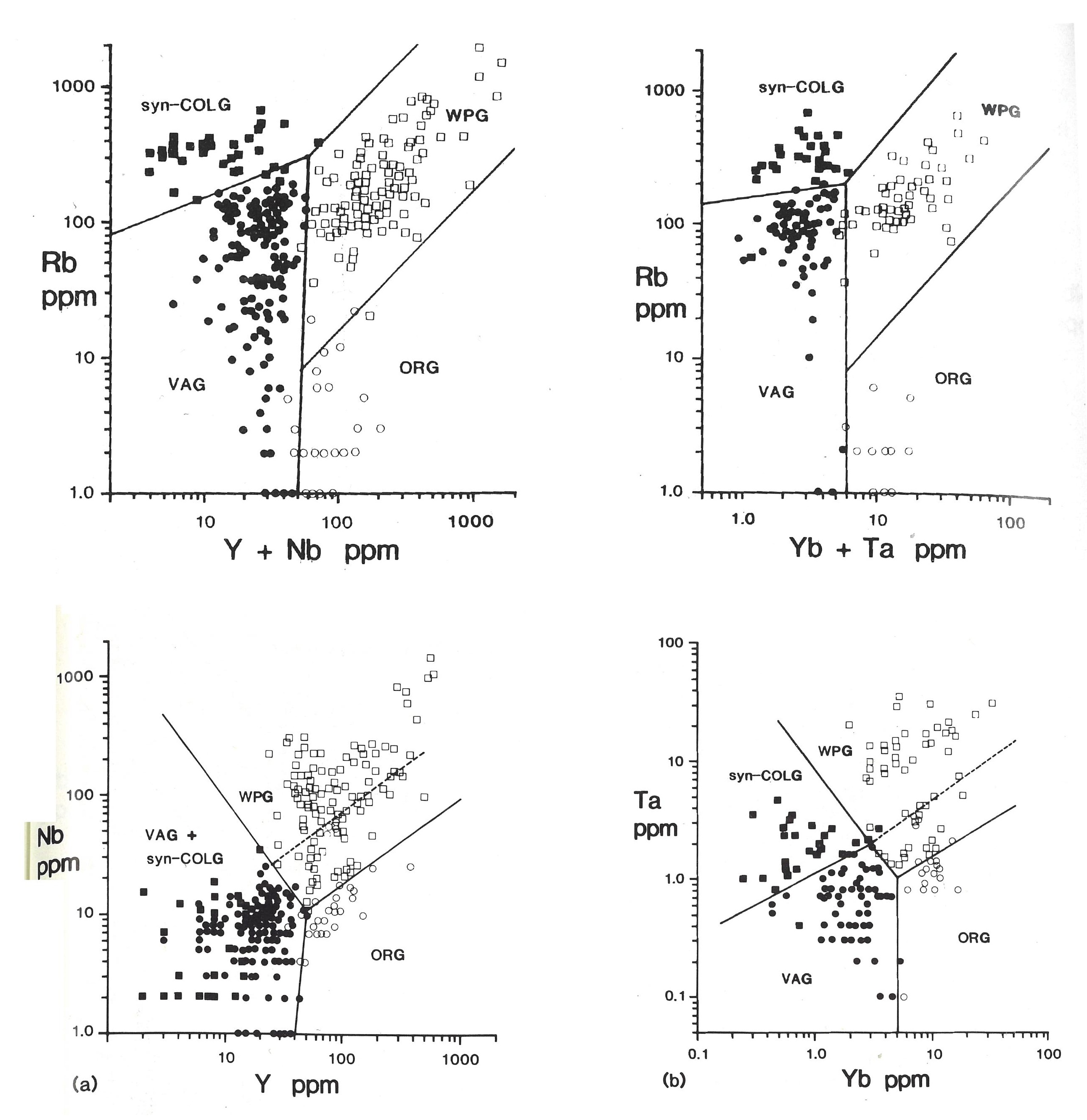

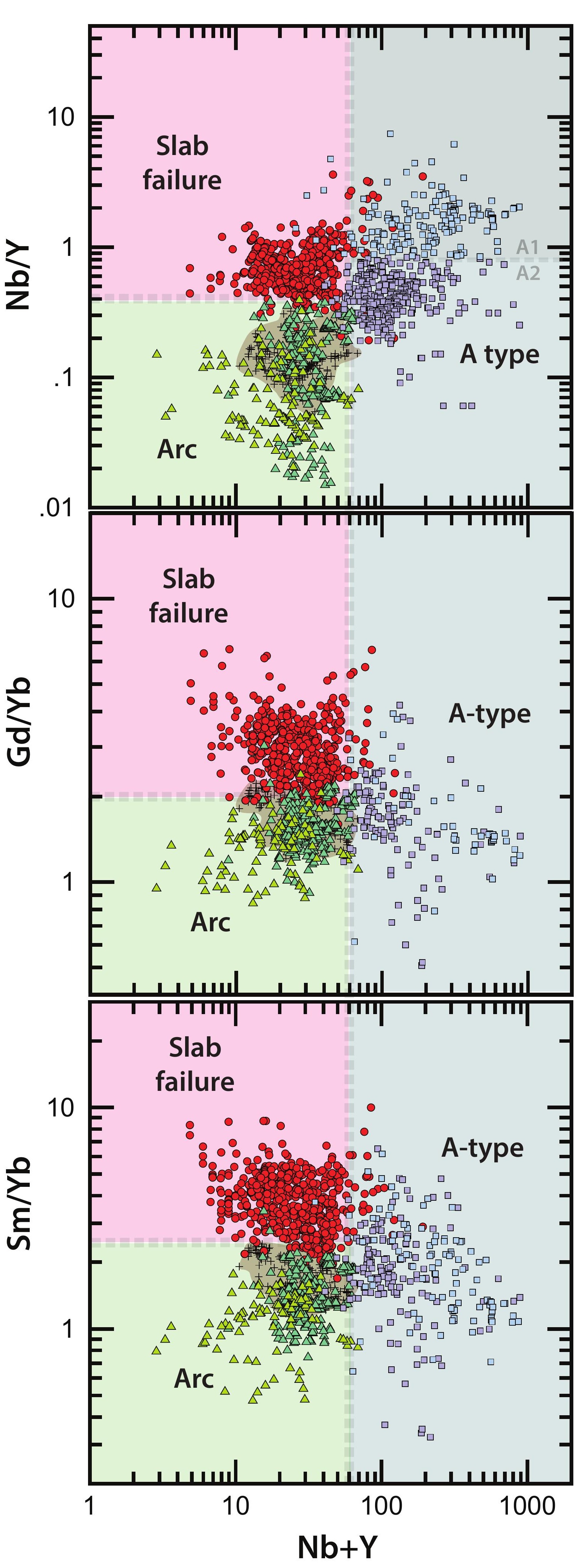
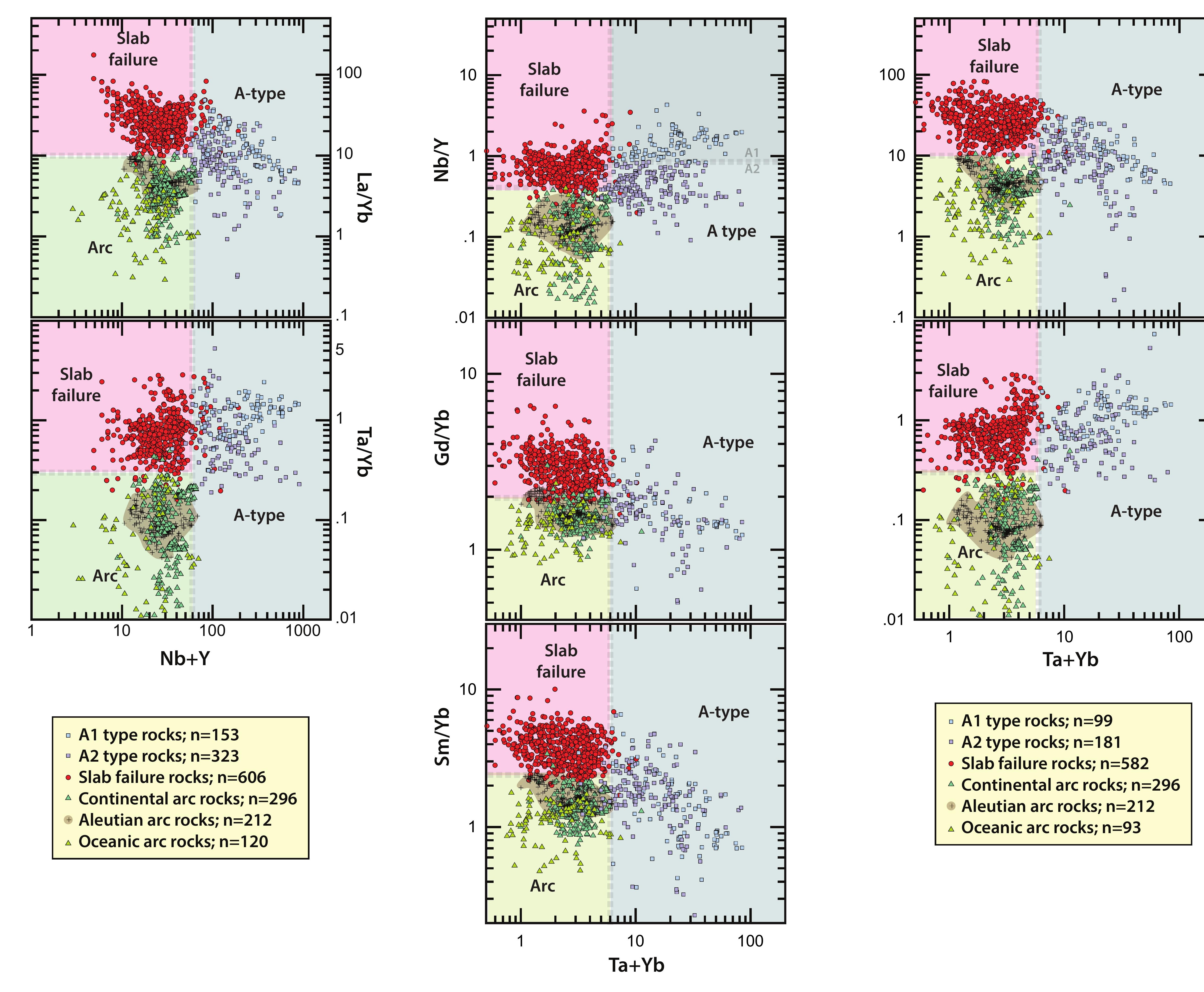

Source of slab failure plutons

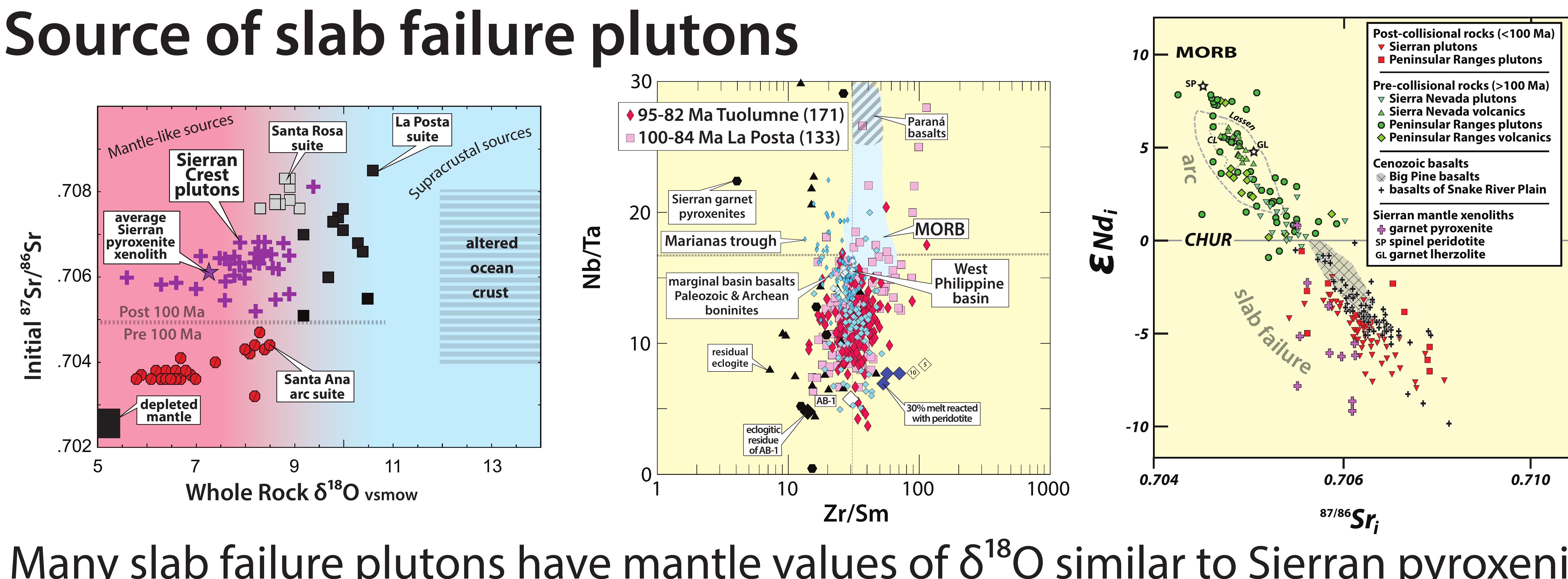

Many slab failure plutons have mantle values of $\delta^{18} \mathrm{O}$ similar to Sierran pyroxenite xenoliths and cannot be products of crustal melting. The plutons are tonalitic to granodioritic and can be derived from melting of garnetiferous and plagioclasefree metabasalt and gabbro. Based on trace element similarities we favor crust of marginal basins over MORB. Rising melts can be modified by fractional melting as they pass through old and enriched subcontinental mantle lithosphere, where they change their isotopic composition as have many basalts of the western US. 